\title{
PEMANFAATAN ANALISIS SENTIMEN UNTUK PEMERINGKATAN POPULARITAS TUJUAN WISATA
}

\section{UTILIZATION OF SENTIMENT ANALYSIS FOR TOURIST DESTINATION POPULARITY RANKING}

\author{
Murnawan $^{1}$, Ardiles Sinaga ${ }^{2}$ \\ ${ }^{1}$ Program Studi Sistem Informasi, Fakultas Teknik - Universitas Widyatama \\ ${ }^{2}$ Program Studi Teknik Informatika, Fakultas Teknik - Universitas Widyatama

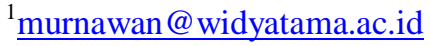

Naskah Diterima: 29 September 2017; Direvisi : 10 Desember 2017; Disetujui : 10 Desember 2017

\begin{abstract}
Abstrak
Saat ini, hampir seluruh industri tidak terkecuali industri pariwisata pasti bersentuhan dengan teknologi informasi. Peranan teknologi sangat erat kaitannya dalam meningkatkan industri pariwisata di Indonesia. Selama berwisata, wisatawan juga dapat membagikan pengalamannya melalui upload foto maupun aktif berkomentar baik di media sosial maupun di forum diskusi yang khusus membahas tentang pariwisata. Informasi seputar kondisi pariwisata, pengalaman wisatawan, opini serta foto yang di upload dari tempat wisata, dapat diolah menjadi suatu informasi yang sangat bermanfaat, salah satunya adalah dapat dimanfaatkan untuk pemeringkatan popularitas. Untuk itu diperlukan suatu sistem yang dapat memberikan informasi tentang popularitas tujuan wisata. Dalam penelitian ini rancangan sistem yang dibuat ini dapat menentukan peringkat tujuan wisata yang paling populer dengan memanfaatkan analisis sentimen. Ada lima komponen penilaian untuk menghasilkan nilai akhir dari peringkat popularitas yaitu comment count, Facebook likes count, Facebook were here count, Facebook talking about dan Instagram visitor. Pada penelitian ini, peneliti memutuskan untuk menggunakan strategi klasifikasi berdasarkan pada algorima naïve bayes (NB) karena merupakan suatu metode yang sederhana dan intuitif yang kinerjanya mirip dengan pendekatan lain. Selain itu, berdasarkan penelitian-penelitian terdahulu, NB menggabungkan efisiensi waktu kinerja yang optimal yang cukup akurat.
\end{abstract}

Kata kunci: analisis sentimen, popularitas, pariwisata, tujuan wisata, Naïve Bayes

\begin{abstract}
Today, almost all industries are no exception to the tourism industry inevitably in contact with information technology. The role of technology in improving the tourism industry in Indonesia is very closely related. During the tour, tourists can also share their experiences through photo uploads and active comments both in social media and in discussion forums that specifically discuss tourism. Information about the condition of tourism, tourist experiences, opinions and photos uploaded from tourist attractions, can be processed into a very useful information, one of which is to be utilized for popularity ranking. For that, we need a system that can provide information about the popularity of tourist destinations. In this study, a system designed to determine the ranking of the most popular tourist destinations by utilizing sentiment analysis. There are five components of the assessment to produce the final value of the popularity ranking of comment count, Facebook likes count, Facebook was here count, Facebook talking about and Instagram visitor. In this study, researchers decided to use a classification strategy based on the algorithm naïve Bayes (NB) because it is a simple and intuitive method whose performance is similar to other approaches. Also, based on previous studies, NB combines optimum performance time efficiency that is quite accurate.
\end{abstract}

Keywords: sentiment analysis, popularity, tourism, tourist destination, Nä̈ve Bayes 


\section{PENDAHULUAN}

Saat ini pertumbuhan pengguna aktif di media sosial mengalami perkembangan yang sangat pesat. Menurut data terbaru dari halaman web We Are Social, pengguna internet aktif berdasarkan platform media sosial di seluruh dunia kini mencapai angka 9,1 miliar. Dari tahun ke tahun, jumlah pengguna internet terus bertumbuh. Menurut laporan yang sama, pengguna media sosial aktif kini mencapai 4,5 miliar, sedangkan pengguna mobile mencapai 4,7 miliar. Sementara itu, Facebook masih menjadi media sosial yang paling banyak digunakan dengan angka hampir mencapai 1,6 miliar pengguna.

Dampak positif media sosial dalam perkembangan information technology sebenarnya membawa banyak keuntungan, misalnya saja memudahkan dalam hal komunikasi, mencari dan mengakses informasi. Salah satu cabang riset yang kemudian berkembang dari situasi ledakan informasi di internet adalah sentiment analysis. Sentiment analysis atau sering disebut juga opinion mining adalah studi komputasional dari opini-opini orang, appraisal dan emosi melalui entitas, event dan atribut yang dimiliki (Liu, 2012).

Adapun penelitian-penelitian terdahulu yang terkait dengan sentiment analysis, antara lain adalah penelitian (Gamallo, Pablo, \& FernandezLanza, 2013) tentang strategy naïve bayes untuk sentiment analysis untuk tweet berbahasa Spanyol. Penelitian (Pak, Alexander and Paroubek, 2010) menganalisis tweeter sebagai linguistik korpus untuk sentiment analysis. Penelitian (Vinodhini and Chandrasekaran, 2012) mengembangkan sistem yang dapat mengidentifikasi dan mengklasifikasikan sentimen masyarakat untuk memprediksi produk yang menarik dalam pemasaran.

Pada penelitian ini, sentiment analysis akan digunakan untuk menentukan peringkat popularitas tujuan pariwisata berdasarkan data komentar atau opini yang terdapat di forum diskusi serta di media sosial yang spesifik membicarakan tentang suatu tempat pariwisata. Pada penelitian ini juga, peneliti memutuskan untuk menggunakan strategi klasifikasi berdasarkan pada algorima Naif Bayes (NB) karena merupakan suatu metode yang sederhana dan merupakan dan intuitif yang kinerjanya mirip dengan pendekatan lain. Selain itu, berdasarkan penelitian-penelitian terdahulu, NB menggabungkan efisiensi (waktu kinerja yang optimal) dengan cukup akurat.

Agar pembahasan lebih terarah dan sesuai dengan apa yang diharapkan maka pada penelitian ini yang menjadi batasan masalah adalah:

1. Sebagai uji coba aplikasi, peneliti menetapkan point of interest (POI) atau spesifik lokasi dari tujuan wisata adalah sebanyak 50 POI di pulau Bali.

2. Data yang dianalisis hanya dalam format bahasa Indonesia dan dengan kata kunci tentang tujuan wisata yang berhubungan dengan POI.

3. Metode klasifikasi yang digunakan untuk mengklasifikasikan komentar-komentar adalah menggunakan Nä̈ve Bayes Classifier.

4. Sebagai sumber data, informasi di crawling dari beberapa forum diskusi dan dari media sosial Facebook dan Instagram.

Adapun tujuan dari penelitian ini adalah membangun suatu aplikasi berbasis web yang dapat menghasilkan informasi tentang peringkat tempat pariwisata yang paling populer di Indonesia 
berdasarkan hasil sentiment analysis terhadap komentar maupun foto yang terdapat pada media sosial.

\section{METODE}

\section{Konsep Sentiment Analysis}

Tugas dasar dalam analisis sentimen adalah mengelompokkan polaritas dari teks yang ada dalam dokumen, kalimat, atau fitur/tingkat aspek dan menentukan apakah pendapat yang dikemukakan dalam dokumen, kalimat atau fitur entitas/aspek bersifat positif, negatif atau netral. Lebih lanjut sentiment analysis dapat menyatakan emosional sedih, gembira, atau marah (Liu, 2012).

Ekspresi atau sentiment mengacu pada fokus topik tertentu, pernyataan pada satu topik mungkin akan berbeda makna dengan pernyataan yang sama pada subject yang berbeda. Sebagai contoh, adalah hal yang baik untuk mengatakan alur film tidak terprediksi, tapi adalah hal yang tidak baik jika 'tidak terprediksi' dinyatakan pada kemudi dari kendaraan. Bahkan pada produk tertentu, kata-kata yang sama dapat menggambarkan makna kebalikan, contoh adalah hal yang buruk untuk waktu start-up pada kamera digital jika dinyatakan "lama", namun jika" lama" dinyatakan pada usia batere maka akan menjadi hal positif.

Hal pertama dalam pemrosesan dokumen adalah memecah kumpulan karakter ke dalam kata atau token, sering disebut sebagai tokenisasi. Tokenisasi adalah hal yang kompleks untuk program komputer karena beberapa karakter dapat dapat ditemukan sebagai token delimiters. Delimiter adalah karakter spasi, tab dan baris baru (newline), sedangkan karakter ( ) $\diamond$ ! ? “ kadang dijadikan delimiter namun, kadang juga bukan, tergantung pada lingkungannya (Triawati, 2009).

\section{Konsep Data Mining}

Data mining adalah proses yang menggunakan teknik statistik, matematika, kecerdasan buatan, dan machine learning untuk mengekstraksi dan mengidentifikasi informasi yang bermanfaat dan pengetahuan yang terkait dari berbagai database besar (Turban \& Liang, 2005).

Istilah data mining memiliki hakikat sebagai disiplin ilmu yang tujuan utamanya adalah untuk menemukan, menggali, atau menambang pengetahuan dari data atau informasi yang kita miliki. Data mining, sering juga disebut sebagai Knowledge Discovery in Database (KDD). KDD adalah kegiatan yang meliputi pengumpulan, pemakaian data, historis untuk menemukan keteraturan, pola atau hubungan dalam set data berukuran besar (Larose, 2005).

\section{Metode Pelatihan Data}

Secara garis besar metode pelatihan yang digunakan dalam teknik-teknik data mining dibedakan ke dalam dua pendekatan, yaitu (Santosa, 2007) :

1. Unsupervised learning, metode ini diterapkan tanpa adanya latihan (training) dan tanpa ada guru (teacher). Guru di sini adalah label dari data.

2. Supervised learning, yaitu metode belajar dengan adanya latihan dan pelatih. Dalam pendekatan ini, untuk menemukan fungsi keputusan, fungsi pemisah atau fungsi regresi, digunakan beberapa contoh data yang mempunyai output atau label selama proses training.

\section{Pengelompokan Data Mining}

Ada beberapa teknik yang dimiliki data mining berdasarkan tugas yang bisa dilakukan, yaitu (Larose, 2005): 


\section{Deskripsi}

Para peneliti biasanya mencoba menemukan cara untuk mendeskripsikan pola dan trend yang tersembunyi dalam data.

2. Estimasi

Estimasi mirip dengan klasifikasi, kecuali variabel tujuan yang lebih kearah numerik dari pada kategori.

3. Prediksi

Prediksi memiliki kemiripan dengan estimasi dan klasifikasi. Hanya saja, prediksi hasilnya menunjukkan sesuatu yang belum terjadi (mungkin terjadi di masa depan).

4. Klasifikasi

Dalam klasifikasi variabel, tujuan bersifat kategorik. Misalnya, kita akan mengklasifikasikan pendapatan dalam tiga kelas, yaitu pendapatan tinggi, pendapatan sedang, dan pendapatan rendah.

\section{Clustering}

Clustering lebih ke arah pengelompokan record, pengamatan, atau kasus dalam kelas yang memiliki kemiripan.

6. Asosiasi

Mengidentifikasi hubungan antara berbagai peristiwa yang terjadi pada satu waktu.

\section{Konsep Nä̈ve Bayes Classifier (NBC)}

Nä̈ve Bayes classifier adalah classifier probabilistik sederhana berdasarkan penerapan teorema Bayes (dari statistik Bayesian) dengan asumsi independen (naif) yang kuat. Sebuah istilah yang lebih deskriptif untuk model probabilitas yang digaris bawahi adalah "model fitur independen".

Dalam terminologi sederhana, sebuah NBC mengasumsikan bahwa kehadiran (atau ketiadaan) fitur tertentu dari suatu kelas tidak berhubungan dengan kehadiran (atau ketiadaan) fitur lainnya. Sebagai contoh, buah mungkin dianggap apel jika merah, bulat, dan berdiameter sekitar 4 inchi. Bahkan jika fitur ini bergantung satu sama lain atau atas keberadaan fitur lain. Sebuah NBC menganggap bahwa seluruh sifat-sifat berkontribusi mandiri untuk probabilitas bahwa buah ini adalah apel.

Tergantung pada situasi yang tepat dari model probabilitas, NBC dapat dilatih sangat efisien dalam supervised learning. Dalam aplikasi praktis, parameter estimasi untuk model NBC menggunakan metode likely hood maksimum, dengan kata lain, seseorang dapat bekerja dengan model Nä̈ve Bayes tanpa mempercayai probabilitas Bayesian atau menggunakan metode Bayesian lainnya (Sumartini Saraswati, 2011).

Dibalik desain naifnya dan asumsi yang tampaknya terlalu disederhanakan, NBC telah bekerja cukup baik dalam banyak situasi dunia nyata yang kompleks. Pada tahun 2004, analisis masalah klasifikasi Bayesian telah menunjukkan bahwa ada beberapa alasan teoritis untuk keberhasilan yang tampaknya tidak masuk akal dari NBC. Selain itu, perbandingan yang komprehensif dengan metode klasifikasi lainnya pada tahun 2006 menunjukkan bahwa klasifikasi Bayes mengungguli pendekatan terbaru, seperti boosted tree atau random forest.

Sebuah keuntungan dari NBC adalah hanya memerlukan sejumlah kecil data pelatihan untuk mengestimasi parameter (rata-rata dan varian dari variabel) yang diperlukan untuk klasifikasi. Karena variabel diasumsikan independen, hanya varian dari variabel untuk setiap kelas yang perlu ditentukan dan bukan keseluruhan covariance matrix. 
Pang, B. and Lee (2008), menyatakan bahwa salah satu core dalam sentiment analysis adalah problem klasifikasi opini. Untuk konteks klasifikasi dokumen teks secara umum (bukan teks opini), misalnya teks berita, metode NBC telah diterapkan oleh beberapa peneliti. Menurut Liu (2012) term sentiment analysis sering digunakan di dunia industri (misalnya review produk untuk mengetahui sentimen pasar). Selanjutnya Liu mendefinisikan opini dalam suatu dokumen sebagai quantuple:

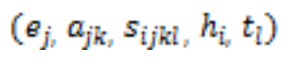

dengan makna simbol:

- ejadalah entitas target opini

- $\quad \mathrm{a}_{j k}$ adalah aspek /feature dari entitas ej

- $\quad \mathrm{s}_{i j k l}$ adalah nilai sentimen dari pemilik opini $\left(\mathrm{h}_{i}\right)$ pada aspek ajk dari entitas ej pada waktu t(opini positif misalnya "bagus", "tepat waktu" ; opini negatif misalnya ("terlambat", "parah")

- $\mathrm{h}_{i}$ adalah pemilik opini

- $\quad \mathrm{t}$ /adalah waktu kapan opini dikeluarkan

Jika opini, pesan atau komentar dianggap sebagai dokumen d, dan diasumsikan dimiliki koleksi dokumen $\mathrm{D}=\left\{\mathrm{d}_{\mathrm{i}}|\mathrm{i}=1,2, \ldots| \mathrm{D} \mid\right\}=\left\{\mathrm{d}_{1}, \mathrm{~d}_{2}, \ldots, \mathrm{d}_{|\mathrm{D}|}\right\}$ dan koleksi kategori $\mathrm{V}=\left\{\mathrm{v}_{\mathrm{j}} \mathrm{j}=1,2, \ldots|\mathrm{V}|\right\}=$ $\left\{\mathrm{v}_{1}, \mathrm{v}_{2}, \ldots, \mathrm{v}_{|\mathrm{V}|}\right\}$. Klasifikasi NBC dilakukan dengan cara mencari probabilitas $\mathrm{P}\left(\mathrm{V}=\mathrm{v}_{\mathrm{j}} \mid \mathrm{D}=\mathrm{d}_{\mathrm{i}}\right)$, yaitu probabilitas kategori $\mathrm{v}_{\mathrm{j}}$ jika diketahui dokumen $\mathrm{d}_{\mathrm{i}}$. Dokumen $\mathrm{d}_{\mathrm{i}}$ dipandang sebagai tuple dari kata-kata dalam dokumen, yaitu $\left\langle\mathrm{a}_{1}, \mathrm{a}_{2}, \ldots, \mathrm{a}_{\mathrm{n}}\right\rangle$, yang frekuensi kemunculannya diasumsikan sebagai variable random dengan distribusi probabilitas Bernoulli (McCallum and Nigam, 1998). Selanjutnya klasifikasi dokumen adalah mencari nilai maksimum dari :

$$
V_{M A P}=\arg _{v j \in \in V} \max P\left(a_{1}, a_{2}, \ldots, a_{n} \mid v_{j}\right)
$$

Dengan menerapkan teorema Bayes persamaan (2) dapat ditulis :

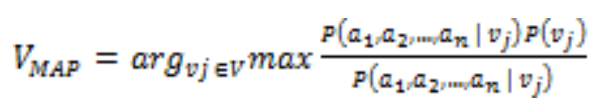

Karena nilai $P\left(a_{1}, a_{2}, \ldots, a_{n}\right)$ untuk semua $v_{\mathrm{j}}$ besarnya sama maka nilainya dapat diabaikan, sehingga persamaan (3) menjadi :

$$
V_{M A P}=\arg _{v j \in V} \max P\left(a_{1}, a_{2}, \ldots, a_{n} \mid v_{j}\right) P\left(v_{j}\right)
$$

Dengan mengasumsikan bahwa setiap kata dalam $<\mathrm{a}_{1}, \quad \mathrm{a}_{2}, \ldots, \mathrm{a}_{\mathrm{n}}>$ adalah independent, maka $\mathrm{P}\left(\mathrm{a}_{1}, \mathrm{a}_{2}, \ldots, \mathrm{a}_{\mathrm{n}} \mid v_{\mathrm{j}}\right)$ dalam persamaan (4) dapat ditulis sebagai :

$$
P\left(v_{j} \mid a_{1}, a_{2}, \ldots, a_{n}\right)=\prod_{i} P\left(a_{i} \mid v_{j}\right)
$$

Sehingga persamaan (4) dapat ditulis :

$$
V_{\text {MAP }}=\underset{\text { arj }}{\arg } \max P\left(v_{j}\right) \prod_{i} P\left(a_{i} \mid v_{j}\right)
$$

Nilai $\mathrm{P}\left(\mathrm{v}_{\mathrm{j}}\right)$ ditentukan pada saat pelatihan, yang nilainya didekati dengan :

$$
P\left(v_{j}\right)=\frac{\left|d o c_{j}\right|}{\mid \text { Contoh } \mid}
$$

dimana $\left|d o c_{\mathrm{j}}\right|$ adalah banyaknya dokumen yang memiliki kategori $\mathrm{j}$ dalam pelatihan, sedangkan |Contoh $\mid$ banyaknya dokumen dalam contoh yang digunakan untuk pelatihan.

Untuk nilai $P\left(w_{k} \mid v_{j}\right)$, yaitu probabilitas kata wk dalam kategori j ditentukan dengan :

$$
P\left(w_{k} \mid v_{j}\right)=\frac{n_{k}+1}{n+\mid \text { vocabulary } \mid}
$$

Dimana $n_{k}$ adalah frekuensi munculnya kata $w_{k}$ dalam dokumen yang ber kategori $\mathrm{v}_{\mathrm{j}}$, sedangkan nilai $\mathrm{n}$ adalah banyaknya seluruh kata dalam dokumen berkategori $\mathrm{v}_{\mathrm{j}}$, dan |vocabulary| adalah banyaknya kata dalam contoh pelatihan.

Naive bayes classifier (NBC) membutuhkan jumlah record data yang sangat besar untuk mendapatkan hasil yang baik. Jika kategori 
prediktor tidak ada dalam data training, maka naive bayes classifier mengasumsikan bahwa record baru dengan kategori predictor memiliki probabilitas nol.

\section{Cara Kerja Algoritma Naive Bayes}

Ada dua tahapan yang dilakukan dalam implementasi algoritma Nä̈ve Bayes, yaitu tahapan pelatihan dan tahapan klasifikasi.

\section{Pelatihan}

Nä̈ve Bayes merupakan algoritma yang termasuk dalam kategori supervised learning, sehingga dibutuhkan pengetahuan awal untuk dapat mengambil keputusan. Adapaun langkah-langkah yang dilakukan adalah:

a. Bentuk vocabulary pada setiap dokumen data training.

b. Hitung probabilitas pada setiap kategori $P(v j)$.

c. Tentukan frekuensi setiap kata wk pada setiap kategori $\mathrm{P}(\mathrm{wk} \mid \mathrm{vj})$.

2. Klasifikasi

Adapun langkah-langkah dalam melakukan klasifikasi adalah:

a. Hitung $\mathrm{P}(\mathrm{vj}) \Pi \mathrm{P}(\mathrm{wk} \mid \mathrm{vj})$ untuk setiap kategori.

b. Tentukan kategori dengan nilai $\mathrm{P}(\mathrm{vj}) \Pi$ $\mathrm{P}(\mathrm{wk} \mid \mathrm{vj})$ maksimal.

\section{Pengumpulan Data}

Secara garis besar, ada dua tahapan dalam proses pengumpulan data yaitu pengumpulan data tujuan wisata serta pengumpulan data sumber melalui proses crawling.

\section{Pengumpulan Data Tujuan Wisata}

Langkah awal yang dilakukan adalah mengumpulkan data point of interest (POI) dari tujuan wisata yang akan dirangking. Pada penelitian ini ditetapkan 50 POI untuk tujuan wisata di pulau Bali berikut dengan koordinat latitude dan longitudenya. Sebagai contoh, data tersebut dapat dilihat pada Tabel 1.

Tabel 1. Contoh Data POI

\begin{tabular}{|l|c|}
\hline \multicolumn{1}{|c|}{ Point of Interest } & \multicolumn{1}{c|}{ Koordinat } \\
\hline Kuta Theater & $-8.729992,115.168106$ \\
\hline Ground Zero & $-8.717369,115.174468$ \\
\hline Bali Shell Museum & $-8.714265,115.186778$ \\
\hline Pura Uluwatu & $-8.817124,115.08854$ \\
\hline Pantai Dreamland & $-8.817124,115.08854$ \\
\hline Tanjung Benoa & $-8.757806,115.219992$ \\
\hline $\begin{array}{l}\text { Pantai Legian dan } \\
\text { Seminyak }\end{array}$ & $-8.780953,115.162895$ \\
\hline Pantai Jimbaran & $-8.723639,115.169588$ \\
\hline $\begin{array}{l}\text { Garuda Wisnu Kencana } \\
\text { Cultural Park }\end{array}$ & $-8.806919,115.164052$ \\
\hline Pantai Kuta & $-8.722314,115.169591$ \\
\hline
\end{tabular}

\section{Pengumpulan Data Source}

Pengumpulan data source dilakukan melalui proses crawling secara online dari beberapa forum diskusi yang telah ditetapkan, dari Facebook dan Instagram.

Ada lima area komponen yang akan menjadi perhitungan perangkingan peringkat popularitas tujuan pariwisata, yaitu:

\section{a. Comment Count}

Merupakan kumpulan dari komentar yang ada di forum diskusi di Indonesia yang khusus membahas tentang satu tempat pariwisata.

Tujuannya adalah untuk melihat apakah satu tempat cukup populer untuk dibahas dalam suatu forum diskusi, dan juga apakah komentar tersebut bermakna positif atau negatif.

b. Instagram Visitor

Merupakan kumpulan data dari pengunggah foto pada website Instagram, dimana aplikasi Instagram telah menyediakan koordinat 
latitude dan longitude dalam meta foto yang diunggah melalui telepon seluler ke website mereka.

Tujuannya untuk mengetahui berapa banyak orang yang mengambil foto di tempat pariwisata berdasarkan latitude dan longitude yang disediakan oleh Instagram.

c. Facebook Likes Count

Merupakan jumlah like dari location yang tersedia di laman Facebook

Tujuannya untuk mendapatkan berapa banyak orang yang menyukai suatu tempat pariwisata tertentu secara massal.

d. Facebook Were Here Count

Merupakan jumlah "were here count" untuk suatu tempat pariwisata.

Tujuannya untuk mendapatkan jumlah banyaknya orang yang pernah mengunjungi suatu tempat pariwisata berdasarkan update status Facebook dari tempat pariwisata tersebut.

\section{e. Facebook Talking About}

Merupakan jumlah orang yang membicarakan suatu tempat pariwisata pada status Facebook mereka.

Tujuannya untuk mendapatkan berapa banyak orang yang melakukan mention tempat pariwisata.

\section{Proses Text Preprocessing}

Proses text prepocessing merupakan implementasi dari text mining untuk memproses suatu teks yang tidak terstruktur menjadi lebih tersruktur atau dengan kata lain mempersiapkan agar teks dapat diubah menjadi lebih terstruktur. Ada empat tahapan text prepocessing yang meliputi case folding, tokenizing, filtering, dan stemming.

\section{Case folding}

Tahapan case folding adalah tahapan untuk mengkonversi keseluruhan teks dalam dokumen menjadi seluruhnya huruf kecil (lowercase). Sebagai contoh, teks "PARIWISATA", "Pariwisata", "PariWisata", atau "pariwisata", tetap diberikan hasil retrieval yang sama yakni "pariwisata". Pada tahapan case folding ini hanya huruf ' $a$ ' sampai dengan ' $z$ ' yang diterima, sedangkan karakter selain huruf dihilangkan dan dianggap delimiter.

\section{Tokenizing}

Tahapan tokenizing adalah tahap pemotongan string input berdasarkan tiap kata yang menyusunnya. Contoh dari tahap ini dapat dilihat pada Gambar 1.

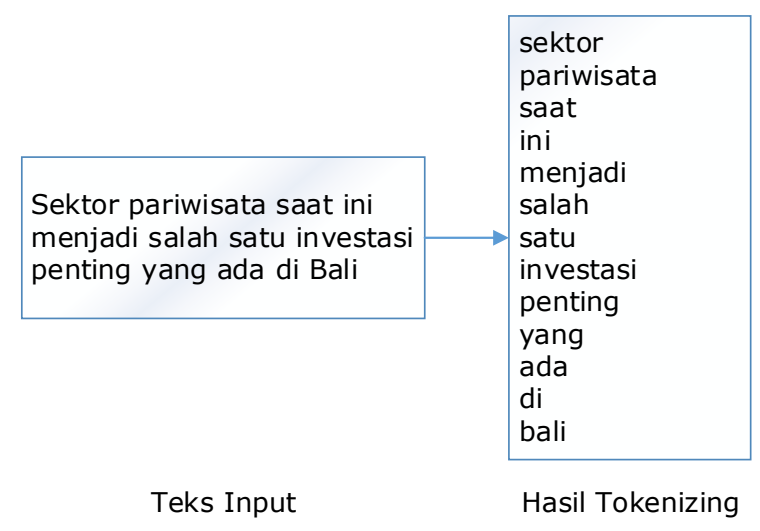

Gambar 1. Proses Tokenizing

Tokenisasi secara garis besar memecah sekumpulan karakter dalam suatu teks ke dalam satuan kata, bagaimana membedakan karakterkarakter tertentu yang dapat diperlakukan sebagai pemisah kata atau bukan.

Sebagai contoh karakter whitespace, seperti enter, tabulasi, spasi dianggap sebagai pemisah kata. Namun untuk karakter petik tunggal ('), titik (.), semikolon (;), titk dua (:) atau lainnya, dapat memiliki peran yang cukup banyak sebagai pemisah kata. 
Dalam memperlakukan karakter-karakter dalam teks sangat tergantung pada kontek aplikasi yang dikembangkan. Pekerjaan tokenisasi ini akan semakin sulit jika juga harus memperhatikan struktur bahasa (grammatikal).

\section{Filtering}

Tahapan filtering adalah tahap mengambil kata-kata penting dari hasil token. Bisa menggunakan algoritma stoplist (membuang kata kurang penting) atau wordlist (menyimpan kata penting). Stoplist/stopword adalah kata-kata yang tidak deskriptif yang dapat dibuang dalam pendekatan bag-of-words. Contohnya dapat dilihat pada Gambar 2.

Contoh stopword s adalah "yang", "dan", “di”, "dari” dan seterusnya (TALA, 2003).

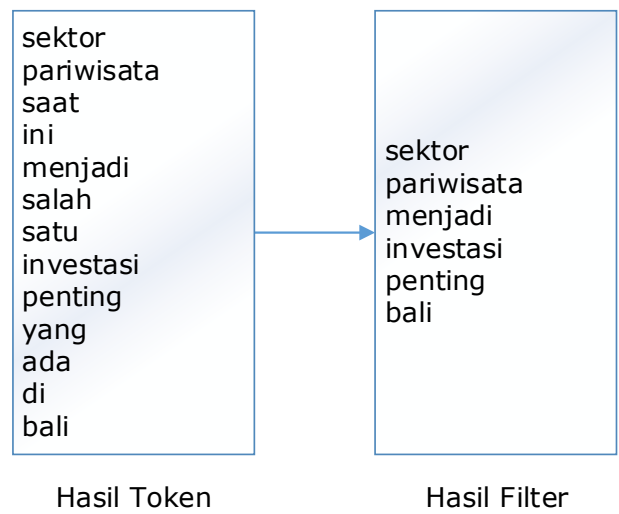

Gambar 2. Proses Filtering

Kata-kata seperti "dari”, "yang”, “di”, dan "ke" adalah beberapa contoh kata-kata yang berfrekuensi tinggi dan dapat ditemukan hampir dalam setiap dokumen (disebut sebagai stopword). Penghilangan stopword ini dapat mengurangi ukuran index dan waktu pemrosesan. Selain itu, juga dapat mengurangi level noise.

Namun terkadang stopping tidak selalu meningkatkan nilai retrieval. Pembangunan daftar stopword (disebut stoplist) yang kurang hati-hati dapat memperburuk kinerja sistem Information Retrieval (IR). Belum ada suatu kesimpulan pasti bahwa penggunaan stopping akan selalu meningkatkan nilai retrieval, karena pada beberapa penelitian, hasil yang didapatkan cenderung bervariasi.

\section{Stemming}

Pembuatan indeks dilakukan karena suatu dokumen tidak dapat dikenali langsung oleh suatu sistem temu kembali informasi atau Information Retrieval System (IRS). Oleh karena itu, dokumen tersebut terlebih dahulu perlu dipetakan ke dalam suatu representasi dengan menggunakan teks yang berada di dalamnya.

Teknik stemming diperlukan selain untuk memperkecil jumlah indeks yang berbeda dari suatu dokumen, juga untuk melakukan pengelompokan kata-kata lain yang memiliki kata dasar dan arti yang serupa namun memiliki bentuk atau form yang berbeda karena mendapatkan imbuhan yang berbeda.

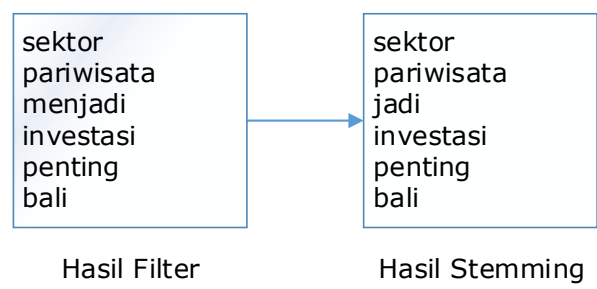

Gambar 3. Proses Stemming

Sebagai contoh kata bersama, kebersamaan, menyamai, akan distem ke root word-nya yaitu "sama". Namun, seperti halnya stopping, kinerja stemming juga bervariasi dan sering tergantung pada domain bahasa yang digunakan.

Proses stemming pada teks berbahasa Indonesia berbeda dengan stemming pada teks berbahasa Inggris. Pada teks berbahasa Inggris, proses yang diperlukan hanya proses 
menghilangkan sufiks. Sedangkan pada teks berbahasa Indonesia semua kata imbuhan baik itu sufiks dan prefiks juga dihilangkan.

\section{Proses Klasifikasi Naüve Bayes}

Tujuan dari proses klasifikasi adalah untuk menentukan sebuah kalimat apakah termasuk sebagai anggota kelas opini positif atau sebagai anggota kelas opini negatif yang ditentukan berdasarkan nilai perhitungan probabilitas Bayes yang lebih besar. Jika hasil probabilitas Bayes kalimat tersebut untuk kelas opini positif lebih besar maka kalimat tersebut masuk kategori opini positif demikian juga sebaliknya.

\section{PEMBAHASAN DAN HASIL}

\section{Implementasi Pada Platform Web}

Untuk menghasilkan informasi popularitas tujuan wisata, hasil sentiment analysis diimplemetasikan secara web based yang dapat dilihat secara publik di alamat http://poi.iniristi.com. Ada dua halaman utama yang paling penting, yaitu halaman informasi peringkat seperti terlihat pada Gambar 6, serta informasi detail dari tujuan wisata seperti terlihat pada Gambar 7.

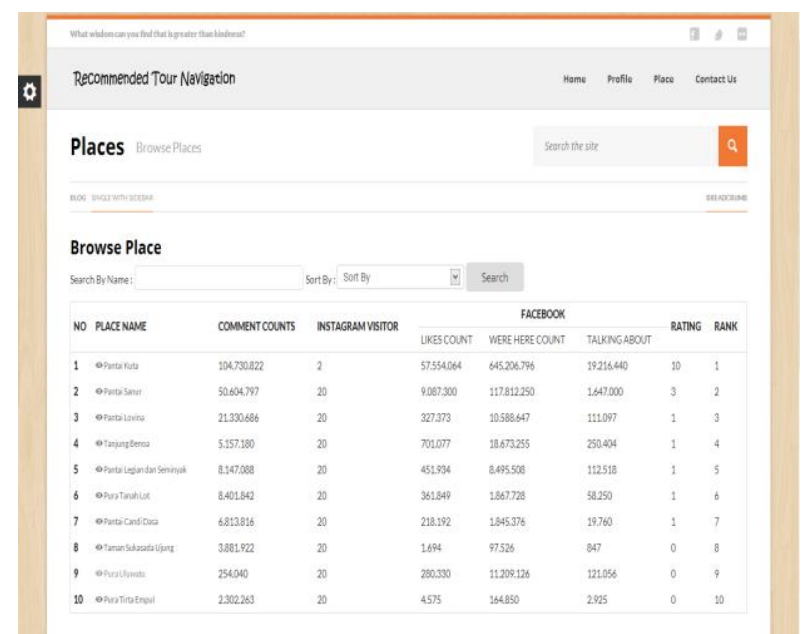

Gambar 6. Peringkat Popularitas Tujuan Wisata
Dari halaman seperti yang terlihat pada gambar 6, kemudian dapat dipilih salah satu tempat tujuan wisata jika ingin melihat detail informasi seperti yang terlihat pada Gambar 7.

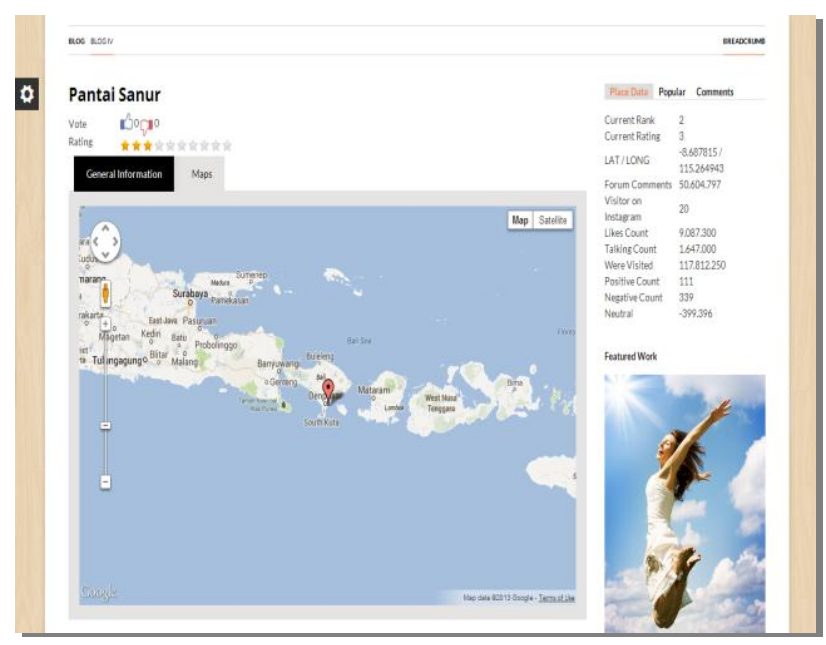

Gambar 7. Detail Informasi

Adapun detail informasi yang ditampilkan adalah posisi tujuan wisata yang terletak pada peta (map) serta informasi dari hasil crawling dan sentiment analysis. Berikut ini data yang ditampilkan:

- Current Rank: 2

- Current Rating : 3

- $\quad$ LAT / LONG : -8.687815 / 115.264943

- Forum Comments : 50.604 .797

- Visitor on Instagram : 20

- Likes Count : 9.087.300

- Talking Count : 1.647 .000

- Were Visited : 117.812.250

- Positive Count : 111

- Negative Count : 339

- Neutral : -399.396

\section{Metode Pemeringkatan}

Metode pemeringkatan secara umum yang dilakukan masih sangat sederhana, dimana tidak ada pembobotan dari masing-masing komponen penilaian. 
a. Skala yang digunakan: $0-10$

b. Masing-masing komponen penilaian dihitung persentase nilai positif dari total data training yang ada.

c. Rating dihitung berdarkan jumlah seluruh data training dibagi jumlah seluruh persentase nilai positif.

d. Kemudian dibuat perangkingannya.

\section{Hasil Pemeringkatan}

Berdasarkan hasil crawling data yang dilakukan terhadap 50 POI, maka untuk sepuluh besar urutan teratas dapat dilihat pada tabel 2.

Tabel 2. Sepuluh Peringkat Tujuan Wisata Terbaik

\begin{tabular}{|c|l|r|r|r|r|r|}
\hline \multirow{2}{*}{ Rank } & \multirow{2}{*}{ Place } & \multirow{2}{*}{ CC } & \multirow{2}{*}{ IV } & \multicolumn{3}{|c|}{ Facebook } \\
\cline { 5 - 7 } & & & \multicolumn{1}{|c|}{ LC } & \multicolumn{1}{c|}{ WH } & \multicolumn{1}{c|}{ TA } \\
\hline 1 & Pantai Kuta & 104.73 & 2 & 57.554 & 645.206 & 19.216 \\
\hline 2 & Pantai Sanur & 50.604 & 20 & 9.087 & 117.812 & 1.647 \\
\hline 3 & Pantai Lovina & 21.33 & 20 & 327 & 10.588 & 111 \\
\hline 4 & Tanjung Benoa & 5.157 & 20 & 701 & 18.673 & 250 \\
\hline 5 & $\begin{array}{l}\text { Pantai Legian } \\
\text { dan Seminyak }\end{array}$ & 8.147 & 20 & 451 & 8.495 & 112 \\
\hline 6 & Pura Tanah Lot & 8.401 & 20 & 361 & 1.867 & 58 \\
\hline 7 & $\begin{array}{l}\text { Pantai Candi } \\
\text { Dasa }\end{array}$ & 6.813 & 20 & 218 & 1.845 & 19 \\
\hline & $\begin{array}{l}\text { Taman } \\
\text { Sukasada }\end{array}$ & & & & & \\
\hline 8 & Ujung & 3.881 & 20 & 1 & 97 & 8 \\
\hline 9 & Pura Uluwatu & 254 & 20 & 280 & 11.209 & 121 \\
\hline 10 & $\begin{array}{l}\text { Pura Tirta } \\
\text { Empul }\end{array}$ & 2.302 & 20 & 4 & 164 & 2 \\
\hline
\end{tabular}

Keterangan tabel:

- Data dalam ribu.

- $\quad$ Rank $=$ Peringkat tujuan wisata

- $\quad$ Place $=$ Tempat tujuan wisata (POI)

- $\mathrm{CC}=$ Comment Count

- $\quad$ IV = Instagram Visitor

- $\quad \mathrm{LC}=$ Like Count

- $\mathrm{WH}=$ Where Here Count

- $\mathrm{TA}=$ Talking About

Secara keseluruhan, hasil pemeringkatan dapat dilihat pada alamat http://poi.iniristi.com.

\section{Hasil Analisis Validitas Data}

Berdasarkan data-data yang dikumpulkan dari beberapa sumber hasil crawling, yaitu dari Facebook, Instagram dan forum diskusi, data konten yang dihasilkan secara jumlah dapat secara langsung dapat dilihat tempat mana yang paling populer, tanpa harus memakai metode yang khusus. Berikut ini salah satu contoh yang didapatkan dari Facebook:

1. Pantai Kuta :
a. Facebook Likes Count
: 57.554 .064
b. Were Here Count
: 645.206 .796
c. Talking About Count
$: 19.216 .440$

2. Pantai Sanur :
a. Facebook Likes Count $\quad: 9.087 .300$
b. Were Here Count
$: 117.812 .250$
c. Talking About Count
$: 1.647 .000$

Dan seperti yang telah dijelaskan sebelumnya, masing masing komponen penilaian memiliki peranannya masing-masing. Khusus untuk komponen penilaian Were Here Count, dimana data langsung didapatkan dari Facebook berdasarkan update status dari setiap orang yang kemudian secara otomatis sistem Facebook menetapkan koordinat latitude dan longitude dari posisi orang tersebut pada saat melakukan update statusnya. Jadi secara tidak langsung, bisa diketahui berapa banyak orang yang pernah mengunjungi POI tersebut.

Bagaimanapun, data dari satu sumber saja tidak dapat langsung membuat sebuah POI menduduki peringkat teratas. Seperti contoh dibawah ini :

1. Taman Sukasada Ujung :
a. Facebook Likes Count : 1.694
b. Were Here Count : 97.526
c. Talking About Count : 847
d. Comment Count : 3.881 .922 
2. Pura Uluwatu :
a. Facebook Likes Count : 280.330
b. Were Here Count : 11.209 .126
c. Talking About Count : 121.056
d. Comment Count : 254.040

Berdasarkan contoh diatas, jika menggunakan data yang diambil dari Facebook saja, sudah jelas bahwa Pura Uluwatu seharusnya berada jauh diatas Taman Sukasada Ujung. Tetapi dengan adanya komponen penilaian Comment Count maka hasil perhitungan akhir mengalami perubahan. Taman Sukasada Ujung memiliki Comment Count yang jauh lebih banyak dibanding Pura Uluwatu. Ini menyatakan bahwa banyak orang yang antusias membahas Taman Sukasada Ujung dibanding Pura Uluwatu.

Algoritma sentiment analyst yang digunakan pada penelitian ini, yaitu algoritma yang mengharuskan penggunanya untuk mengumpulkan frase sebanyak-banyaknya, sehingga keakurasian sentiment yang didapat bisa menghasilkan keakuratan yang semaksimal mungkin. Dari algoritma yang digunakan, berdasarkan hasil uji coba yang dilakukan ada beberapa data tingkat keakuratan sentiment yang didapat:

a. 100 Phrase,

$$
\text { Accuracy } \quad: 0.65653495440729(65.65 \%)
$$

b. 5000 Phrase,

$$
\text { Accuracy : } 0.82674772036474(82.67 \%)
$$

Dari data diatas dapat lihat bahwa semakin banyak frase yang dimiliki sebagai core dari algoritma tersebut, maka semakin akurat sentiment analysis yang disajikan.

\section{Perbandingan Rating Secara Umum}

Berdasarkan kenyataan yang ada, diketahui bahwa POI yang paling popular di Pulau Bali merupakan Pantai Kuta Bali. Banyak yang berkunjung ke Bali yang mengatakan bahwa "Bukan ke Bali kalau tidak berkunjung ke Pantai Kuta", dan slogan tersebut sangat popular dikalangan para wisatawan.

Sebagai perbandingan, hasil pada penelitian ini dicoba dibandingkan dengan salah satu situs web pariwisata yang cukup terkenal yaitu Tripadvisor. Pada Tripadvisor, Pantai Kuta lebih popular dibanding Pantai Sanur. Sedangkan pada hasil penelitian yang kami lakukan, peringkat tersebut sering berganti-ganti. Hal ini bisa disebabkan karena masalah konsistensi proses crawling data serta jumlah data dan sumber data yang berbeda. Selain itu, perbedaan metodologi perhitungan pemeringkatan yang digunakan juga sangat mempengaruhi hasil pemeringkatan.

\section{PENUTUP}

Berdasarkan hasil analisis uji validitas data, algoritma yang digunakan sudah cukup memiliki akurasi yang baik dan dapat diterima sebagai suatu metode perhitungan pemeringkatan.

Khususnya dalam domain pariwisata, komponen-komponen penilaian yang digunakan sudah dapat memberikan penilaian yang lebih objektif yang dihasilkan berdasarkan konten opini atau ulasan dari media sosial maupun situs pariwisata lainnya. Dengan mengambil data uji terhadap 50 point of interest (POI) tujuan wisata di Pulau Bali, hasil ekstraksi dan klasifikasi opini maupun ulasan yang berkitan dengan destinasi wisata di pulau Bali tersebut menghasilkan peringkat popularitas yang dapat menjadi bahan pertimbangan bagi wisatawan sebagai tujuan wisata mereka.

Ada beberapa saran agar hasil penelitian ini dapat lebih baik lagi, yaitu: 
1. Penelitian selanjutnya dapat dikembangkan dengan menambah beberapa fitur pada aplikasi

2. Perlu ada perbaikan dalam metodologi pemeringkatan yang digunakan, agar hasil pemeringkatan dapat lebih akurat dan lebih baik lagi.

3. Menambah metodologi business intelegent (BI) yang dapat digunakan sebagai alat bantu pengambilan keputusan bagi yang berkepentingan, dalam hal ini khususnya pemerintah sebagai stakeholder destinasi wisata.

\section{UCAPAN TERIMA KASIH}

Peneliti mengucapkan terima kasih kepada pihak-pihak telah membantu untuk menyelesaikan penelitian ini.

\section{DAFTAR PUSTAKA}

Gamallo, Pablo, \& Fernandez-Lanza. (2013). TASS: A Naive-Bayes strategy for sentiment analysis on Spanish tweets. In In Workshop on Sentiment Analysis at SEPLN (TASS2013) (pp. 126-132). Madrid, Spain. yang dibangun agar lebih baik lagi.

Larose, D. T. (2005). Discovering Knowledge in Data: An Introduction to Data Mining. John Willey \& Sons, Inc.

Liu, B. (2012). Opinion Mining. Chicago, United States of America.

Pak, Alexander and Paroubek, P. (2010). Twitter as a Corpus for Sentiment Analysis and Opinion Mining. In In LREC-2010. Valletta, Malta.

Pang, B. and Lee, L. (2008). Opinion mining and sentiment analysis in Foundations and Trends in Information Retrieval.

Santosa, B. (2007). Data mining teknik pemanfaatan data untuk keperluan bisnis. Yogyakarta: Graha Ilmu.

Sumartini Saraswati, N. W. (2011). Text Mining dengan Metode Naive Bayes Classifier dan Support Vector Machines untuk Sentiment Analysis. Denpasar, Bali, Indonesia.

TALA, F. Z. (2003). A Study of Stemming Effects on Information Retrieval in Bahasa Indonesia. Universiteit van Amsterdam.

Triawati, C. (2009). Text Mining. Bandung, Jawa Barat, Indonesia.

Turban, E., \& Liang, J. E. A. and T. P. (2005). Decision Support System and Intelligent Systems (7th ed). Pearson Education, Inc. 